Proceedings of 2002 IGTI

International Gas Turbine Conference and Exposition June 3-6, 2002, Amsterdam

GT-2002-30212

\title{
HEAT TRANSFER IN A COMPLEX TRAILING EDGE PASSAGE FOR A HIGH PRESSURE TURBINE BLADE - PART 1: EXPERIMENTAL MEASUREMENTS
}

\author{
Ronald S. Bunker and Todd G. Wetzel \\ General Electric R\&D Center \\ Schenectady, New York 12301 \\ David L. Rigby \\ QSS, Inc. \\ NASA Glenn Research Center \\ Cleveland, Ohio 44135
}

\begin{abstract}
A combined experimental and computational study has been performed to investigate the detailed heat transfer coefficient distributions within a complex blade trailing edge passage. The experimental measurements are made using a steady liquid crystal thermography technique applied to one major side of the passage. The geometry of the trailing edge passage is that of a two-pass serpentine circuit with a sharp 180-degree turning region at the tip. The upflow channel is split by interrupted ribs into two major subchannels, one of which is turbulated. This channel has an average aspect ratio of roughly 14:1. The spanwise extent of the channel geometry includes both area convergence from root to tip, as well as taper towards the trailing edge apex. The average section Reynolds numbers tested in this upflow channel range from 55,000 to 98,000 . The tip section contains a turning vane near the extreme corner. The downflow channel has an aspect ratio of about 5:1, and also includes convergence and taper. Turbulators of varying sizes are included in this channel also. Both detailed heat transfer and pressure distribution measurements are presented. The pressure measurements are incorporated into a flow network model illustrating the major loss contributors.
\end{abstract}

\section{INTRODUCTION}

The need for improved internal cooling methods for high temperature gas turbine components has been well remarked over the past thirty years. The objectives at the engine level include higher efficiency, lower emissions, lower fuel consumption, extended hot section airfoil life (durability and reliability), as well as other mission specific metrics. Designers of turbine airfoils (vanes and blades) are asked to maintain or reduce bulk temperature levels with less cooling air, and to do so while also extending the life of the part. Aside from the appropriate use of materials, protective coatings, and film cooling, internal cooling provides the backbone of the components fluid network for distribution and control of thermal response. While mechanisms to improve the magnitude of heat transfer, both structural and fluid dynamic, are the focus of the majority of research, an understanding of the local and global distribution and gradients in heat transfer coefficients within complex geometries is equally important. Typically, the details associated with the use and distribution of cooling methods within actual turbine airfoils is the domain of the industrial designer. But as computational fluid dynamics (CFD) methods mature, there is an increasing need for experimental validation data to be obtained within realistic geometric models of the internal cooling circuits of production turbine airfoils.

Many studies, both experimental and computational, exist in the literature concerning fundamental means for enhancing internal heat transfer within dominantly turbulent flow configurations. These include turbulation of passages by various repeated surface features, impingement jets and arrays of jets, swirling flows, pin-banks, roughness, and much more. There are far too many references to be mentioned here, but reviews of these methods and investigations may be found in Han and Dutta [1], and also Weigand et al. [2].

One of the most common means for enhancing heat transfer coefficients within internal passages, and especially the serpentine passages of many turbine blade designs, is the use of turbulators, also known as rib rougheners. Turbulators were one of the first improvements made to the cooling of blades, and hence many investigations have been made into the heat transfer and friction characteristics of various forms of turbulators. Basic turbulator research leading to widely used data and correlations was performed by Webb et al. [3], Burggraf [4], and Han et al. [5,6]. These and 
other researchers have concentrated on turbulators of relative height e/D less than 0.2 , but greater than that typically associated with uniform surface roughness. The general findings of all such research has been that surface averaged heat transfer coefficients within stationary, turbulated passages may be enhanced by factors from 1.8 to 2.8 , while the friction factors or required pumping power are increased by factors of 3 to 10 . Many parameters are variable in turbulated passages, and many more in serpentine circuits, but the range of effects has remained much the same over the years.

More recently, investigations have been focused on the details of heat transfer and flow distributions within turbulated channels and multi-pass circuits, and the use of this data in improving and validating CFD predictions. Examples of such studies are Rau et al. [7], Schabacker et al. [8], Shih et al. [9], and Chen et al. [10]. Other studies, fewer in number, have sought to provide detailed heat transfer coefficient distributions within multi-pass serpentine turbulated cooling circuits. The investigations of Chyu and Natarajan [11] and also Funazaki et al. [12] showed detailed heat transfer distributions within three-pass serpentines representative of blade midchord cooling circuits. These studies showed the enhancements not only due to the turbulators, but also the combined effects of turns and turbulators in maintaining elevated heat transfer levels.

Only a very few studies have looked specifically at the internal passages of the narrow blade trailing edge region. Taslim et al. [13] obtained local heat transfer coefficient distributions within a trailing edge model with a turbulated passage fed on one side by crossover impingement jets, and bled on the other side by trailing edge holes. This model was a trapezoidal version of a trailing edge, with average aspect ratio of roughly 6:1 (width-to-height). The focus of this study was on the effect of impingement and bleed, not on serpentine convection. Abuaf and Kercher [14] obtained full-surface heat transfer coefficients in a complete blade model with a three-pass serpentine cooling circuit, fully turbulated. The trailing edge passage in this case exited out several trailing edge holes, and had an average aspect ratio of 5.75:1. Heat transfer enhancements over those of a smooth duct were shown to range from 3 to 5 , and included the effects of turbulators and turns together. Comparisons with CFD of the same geometry generally showed discrepencies of 30 to $60 \%$.

The present study utilizes a detailed model of a blade trailing edge region, incorporating a two-pass serpentine with complex internal geometry, to obtain distributions of heat transfer coefficients and static pressures. Trailing edge bleed holes are not present in this study, such that the focus is maintained on only the internal convective effects due to turbulators, split channels, and the tip turning region. A very high aspect ratio trailing edge passage of $14: 1$ is used with convergence of walls in two directions. This very realistic model demonstrates the challenges involved in design, and provides validation data for the CFD predictions of Part 2.

\section{EXPERIMENTAL APPARATUS AND METHOD}

The test model for this study is depicted in Figure 1. The main top and bottom surfaces of the model are made from acrylic sheet material with thickness of $5.08 \mathrm{~cm}$. The cooling passages are of trapezoidal shape, both the up-passage 1 and the down-passage 2 . These two main passages forming the serpentine are divided by a single separating rib of $3.18-\mathrm{mm}$ thick balsa wood. Passage 1 is further divided as a split passage $1 \mathrm{~A}$ and $1 \mathrm{~B}$ with a segmented separating rib which allowed flow to move from $1 \mathrm{~B}$ into $1 \mathrm{~A}$ as dictated by the resistance set up in the $1 \mathrm{~B}$ turbulated region. These segmented dividing ribs were also 3.18 -mm thick balsa wood. These ribs and the top of the main divider all had rounded ends of full radius. A turning vane of balsa wood was located in the trailing edge tip corner with the location and shape shown. As depicted in the inlet cross-section of Figure 1, the upper surface slopes continuously from Passage 2 to the trailing edge apex, forming the 14:1 aspect ratio in Passage 1. In addition to this slope, the passages also converge in the direction from root to tip of the model. This can be seen in the individual passage areas and hydraulic diameters of Table 1. The convergence is quite severe, but representative of an actual turbine blade.

The lower surface of the model is flat. This is the surface on which a thin-foil heater is mounted. As shown in Figure 1, the first third of the test section is unheated. This entry region provides the hydrodynamic development region for the flow. The inlet to Passage 1 is also provided with a small shaped plenum chamber (not shown) which supplies the pressurized air. The upper two-thirds of the model flat wall is heated with a custom made heater of $0.0127-\mathrm{mm}$ thick Inconel in the trapezoidal shape. This heater was verified to provide uniform heat flux over the area. Power supply bus bars are located along both sides of the model in the spanwise direction.
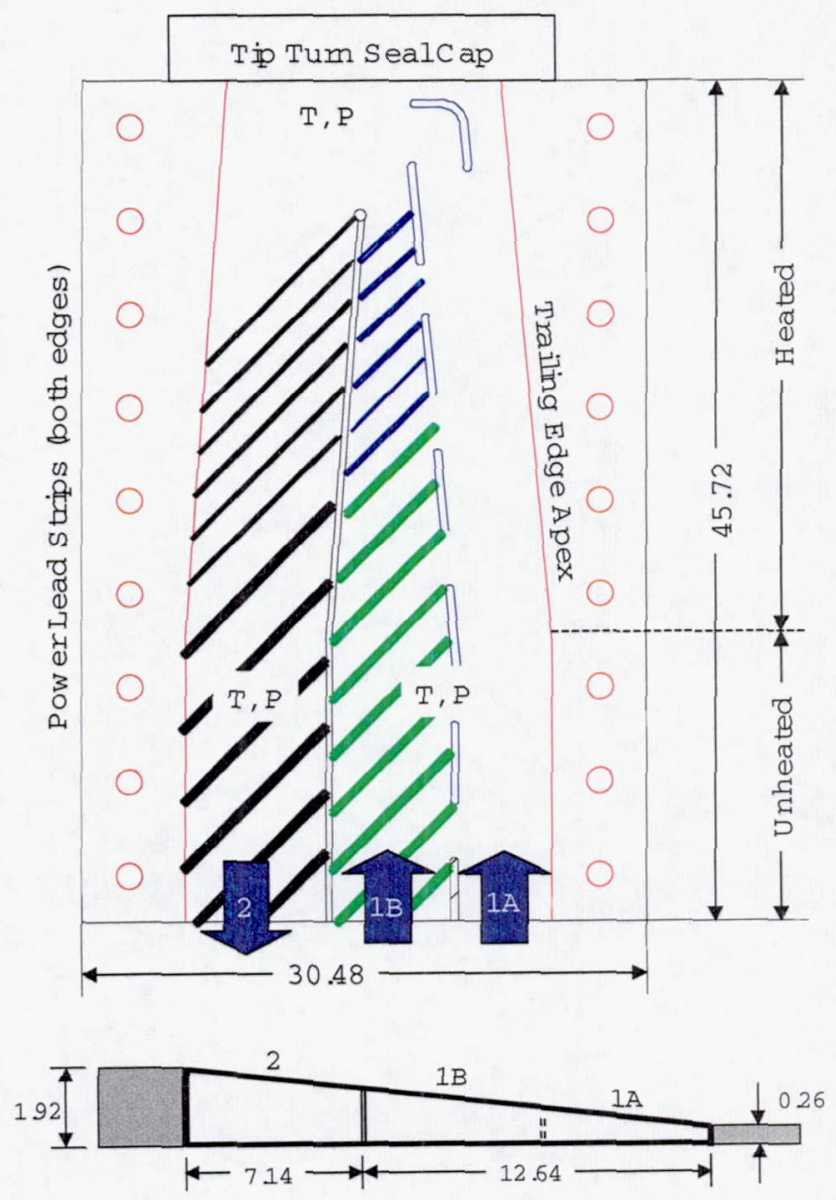

Figure 1. Test Section and Inlet Cross-Section (dimensions in centimeters) 


\begin{tabular}{|c|c|c|c|c|c|}
\hline Channel1A & $\begin{array}{l}\text { Area (cm 2) } \\
\text { Channel1B }\end{array}$ & Channel2 & Channel1A & $\begin{array}{l}\text { Hydraulic } \\
\text { Dia. (cm) } \\
\text { Channel1B }\end{array}$ & Channel2 \\
\hline 2.13 & 7.35 & 11.48 & 0.84 & 1.80 & 2.74 \\
\hline 2.13 & 729 & 11.16 & 0.84 & 1.78 & 2.67 \\
\hline 2.13 & 7.16 & 1084 & 0.84 & 1.75 & 2.62 \\
\hline 2.06 & 697 & 10.52 & 0.81 & 1.70 & 254 \\
\hline 2.06 & 6.77 & 1019 & 0.81 & 1.65 & 2.49 \\
\hline 2.00 & 6.45 & 9.74 & 0.79 & 1.60 & 239 \\
\hline 1.94 & 6.32 & 9.61 & 0.76 & 1.55 & 2.34 \\
\hline 1.94 & 5.74 & 929 & 0.76 & 1.50 & 226 \\
\hline 194 & 5.16 & 890 & 0.76 & 1.47 & 218 \\
\hline 1.94 & 4.71 & 8.58 & 0.76 & 1.42 & 211 \\
\hline 194 & 4.13 & 8.19 & 0.76 & 1.35 & 2.01 \\
\hline 1.87 & 3.42 & 7.68 & 0.74 & 122 & 191 \\
\hline 1.87 & 3.03 & 7.42 & 0.74 & 1.19 & 183 \\
\hline 1.81 & 2.58 & 7.03 & 0.74 & 1.12 & 1.73 \\
\hline 1.81 & 2.13 & 6.71 & 0.71 & 1.07 & 1.65 \\
\hline 1.81 & 1.81 & 6.39 & 0.71 & 0.99 & 1.57 \\
\hline
\end{tabular}

Table 1. Inlet to Tip Channel Section Flow Areas and Hydraulic Diameters (measured at 2.54-cm intervals from the inlet plane)

Turbulators are located in Passages 1B and 2. Both opposing surfaces have turbulators, which are staggered with respect to the opposite wall turbulators, and at 45-deg angle to the main flow. The heavy turbulators shown in Passage $1 \mathrm{~B}$ have height $\mathrm{e}=2 \mathrm{~mm}$ and $\mathrm{P} / \mathrm{e}=10.9$, while those in Passage 2 have $\mathrm{e}=2.5 \mathrm{~mm}$ and $\mathrm{P} / \mathrm{e}=10$. The upper six turbulators shown in Passages $1 \mathrm{~B}$ and 2 have $\mathrm{e}=1.5 \mathrm{~mm}$ and $P / e=9.7$. Because of the model channel convergence and taper, the $\mathrm{e} / \mathrm{D}$ ratios are variable throughout the model, ranging from 0.09 to 0.15 .

All tests were run by maintaining a steady mainstream flow at the desired Reynolds number, and varying the heater power to allow various regions of the liquid crystals to display. The typical heater input power ranged from 100 to $900 \mathrm{~W}$ over a total surface area of $523 \mathrm{sq}-\mathrm{cm}$. Inlet total pressures varied from $129.8 \mathrm{kPa}$ to $184.5 \mathrm{kPa}$ for the inlet Reynolds number from 46,500 to 83,500 . Flow rates for this range were from 0.05 to $0.095 \mathrm{~kg} / \mathrm{sec}$. The inlet total temperature was $24 \mathrm{deg} \mathrm{C}$. Air temperatures were measured in the inlet, tip turn, and exit as denoted by 'T' in Figure 1.

Wall surface temperature distributions are obtained through the use of a calibrated liquid crystal sheet placed between the heater and the acrylic wall. The foil heater is deposited on a thin layer of Kapton. A double-sided adhesion film is used on both sides of the liquid crystal sheet for mounting. The liquid crystals used in this study are wide band 40 to $45 \mathrm{C}$ crystals made by Hallcrest (R40C5W). The liquid crystals are encapsulated in two 5-mil thick layers of Mylar. Figure 3 shows a typical image of the heated surface, clearly showing the features of the geometry. The thermal entry region from the heater front edge in Passage 1 is very short.

The general Hue Intensity method as described by Hollingsworth et al. [15] and Farina and Moffat [16] was used to deduce temperature from the liquid crystal responses. A separate calibration test stand was utilized for the sheet of liquid crystals applied to the model, to determine the hue-temperature calibration curves. Liquid crystal calibrations followed the illuminant invariant method of Farina et al. [17]. Each heat transfer contour plot shown in this study is the result of multiple images obtained with differing heat fluxes which are combined together. The agreement in data within the overlapping regions of individual images is always found to be excellent. The definition of the local heat transfer coefficient in this study is

$$
h=Q_{\text {wall }} /\left(T_{\text {surface }}-T_{\text {air }}\right)
$$

where $\mathrm{Q}_{\text {wall }}$ is the input heater power per unit area, and $\mathrm{T}_{\text {surface }}$ is the liquid crystal indicated temperature. In the present results, $T_{\text {air }}$ is the average value of the three air thermocouples located in the model. This average value was selected as representative of the entire test channel, since there is only a small $<3$-deg $\mathrm{C}$ rise due to heating. Due to the thickness of the acrylic model, heat losses to the room were determined to be negligible. Also, heat losses via the copper buss bars are negligible, due to the small exposed relative surface area $(\sim 0.5 \%)$ and the much lower temperature of the bars. The experimental uncertainty in local heat transfer coefficient defined in this manner is typically $\pm 8 \%$ to $10 \%$, with a confidence level of $95 \%$, as determined by the single-sample method of Kline and McClintock [18].

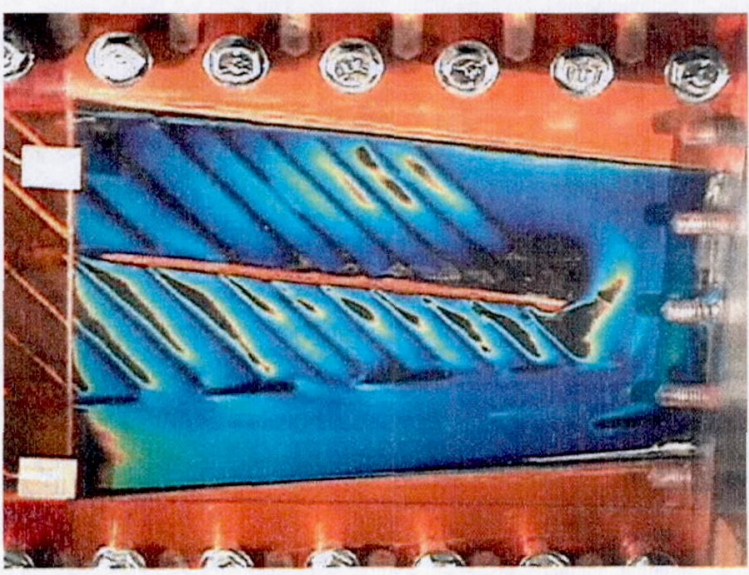

Figure 3. Steady-State Liquid Crystal Test

\section{RESULTS AND DISCUSSION}

\section{Pressure Distributions and Flow Network}

Pressures were measured at 35 taps distributed throughout the model, as shown in Figure 4. These 35 taps were hooked up to one of two 20 psi pressure transducers through two Scanivalve systems. Taps 1 through 20 were connected to pressure transducer 1 through Scanivalve 1, and taps 21 through 35 were connected to transducer 2 through Scanivalve 2. The transducers were calibrated for each test, and had a pressure measurement uncertainty of $+1-0.69 \mathrm{kPa}$. Air flow was measured with a venturi flow meter upstream of the model. Its flow uncertainty is $+1-3 \%$ of the measured value. Comparison of Figure 4 to Figure 1 shows which measurements were in turbulated regions. For these regions, pressure taps were always located midway between turbulators to avoid any local recirculating or separated flows.

Figure 5 presents the model local pressures for all three tested flow rates, shown as local static pressure normalized to inlet total pressure. The inlet total pressure is measured in the shaped entry plenum chamber. Location refers to the pressure tap number in Figure 4. In general, the pressure differences between Passages $1 \mathrm{~A}$ and $1 \mathrm{~B}$ are small, except very near the tip region. The resistance due to the turbulators should result in some fluid being driven from $1 \mathrm{~B}$ to $1 \mathrm{~A}$, which is born out in the higher pressures indicated in $1 \mathrm{~B}$, although these data can not by themselves indicate flow rate quantity. 
Most of the pressure drop is of course occuring in the tip turn region. The pressure data in Passage 2 seem to indicate that the flow recovers by pressure tap 34, which is roughly 8 hydraulic diameters downstream from the start of this channel.

A one-dimensional, multi-element flow model of these channels was constructed and calibrated against the measured pressure data. Geometry from the model was entered, as were the flow boundary conditions and empirical friction multiplication factors for the turbulated passages drawn from a database based upon many literature references. This model was then used to estimate the flow splits between Passages 1A and 1B, which is useful for estimating the ratio of heat transfer between these two passages. Figure 6 shows this flow split along with the area distribution. As indicated in the pressure data, the flow model predicts Passage 1B ingests nearly $80 \%$ of the total flow at the inlet, but near the tip of this passage the mass flow split between $1 \mathrm{~A}$ and $1 \mathrm{~B}$ is roughly the same. The area ratios likewise have the same endstates: Passage 1B owns $80 \%$ of the total Passage 1 area at the inlet, but only occupies $50 \%$ of the area at the end of the passage. But the flow and area distributions follow different trends over the midsection of the passage. Therefore, the local velocities, and thus the local heat transfer coefficients, can be expected to follow different trends as well.

The pressure locations 23-25 around the tip turning vane remain at a pressure level similar to that near the exit of Passage 1 . The most that these measurements indicate is that flow is active in the region, with no gross stagnation zone. Location 26 indicates the jetting flow downstream of the turning vane. Locations $27-29$ proceed from the tip of the central divider to the downstream corner of the tip turn, and so show the varying strength of the local flow turning, with high velocity around the divider and lower velocity in the far corner.

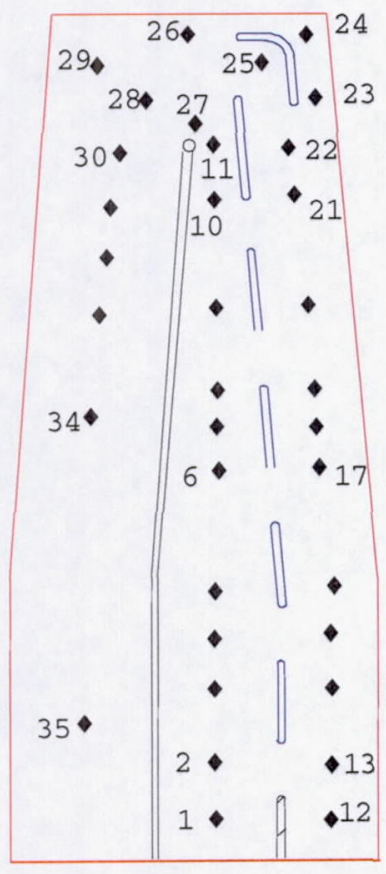

Figure 4. Static Pressure Measurement Locations

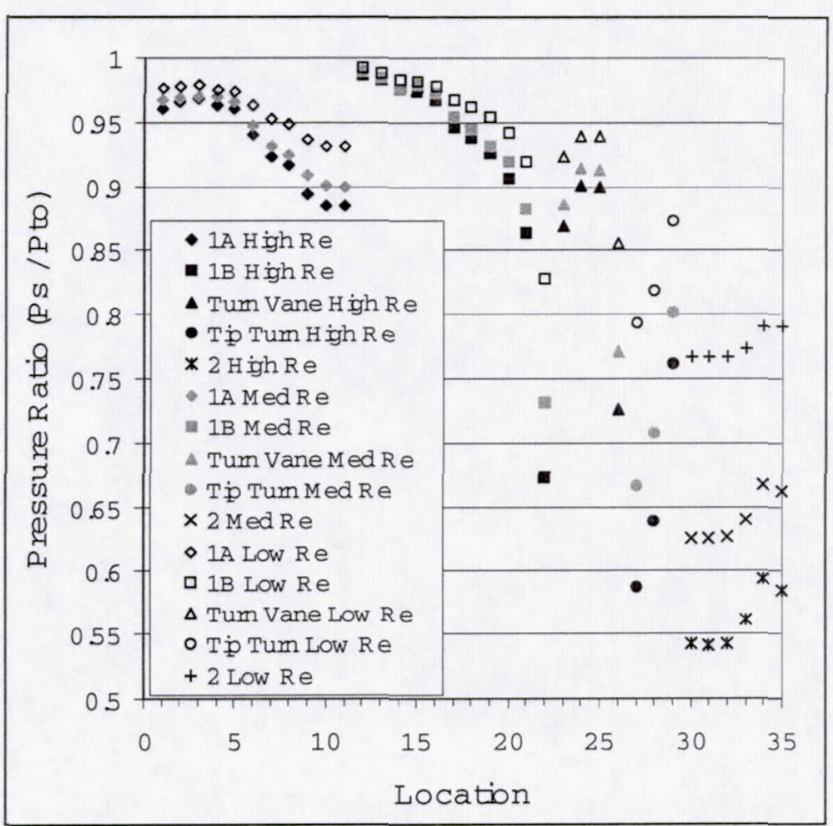

Figure 5. Normalized Channel Pressure Distribution (location refers to the tap number in Fig. 4)

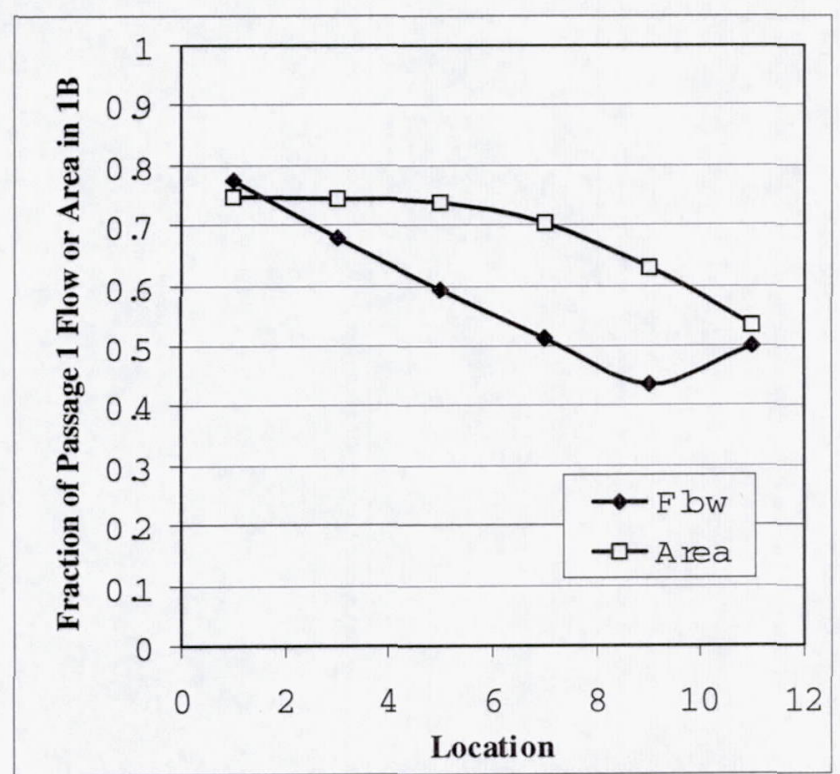

Figure 6. Flow Network Model Prediction of Changes in Passage 1 (location refers to the tap number in Fig. 4)

\section{Heat Transfer Coefficient Distributions}

The flow distribution information derived from model static pressure measurements has already provided some insight into the expected high and low regions of heat transfer coefficients. Figure 7 shows the full-surface heat transfer coefficients for the highest model flow rate condition, which results in a Passage 1 inlet Re of 83,500. In this figure, the approximate outline of divider ribs, turbulators, and tip turning vane has been overlaid as a visual aid. Any appearance of 
heat transfer inside these outlines is due to the liquid crystal color change from heat conduction, not from convection under the features. The three white regions at the tip cap are the bolt holes for the cap. Other regions of white which appear inside the crystal red contours (typically between turbulators) are areas of very high heat transfer coefficient (off-scale). Data was not obtained in such areas due to the danger of overheating the materials.

Several characteristics of heat transfer in the trailing edge serpentine model are immediately apparent from Figure 7. Remember, there is an additional turbulated flow development region upstream of Passage 1, and downstream of Passage 2. The most highly cooled region is that of Passage $1 \mathrm{~B}$, and in particular at the region nearing the tip turn where the passage is at its minimum area. Passage 1A has declining heat transfer levels approaching the tip region, showing the difficulty of getting flow into the narrow trailing edge apex. The turning vane is essentially surrounded by the lowest heat transfer levels in the entire model. While flow is present in the extreme corner, it is not of high strength. The turning vane is seen to have a large, well-defined wake region with enhanced heat transfer in the upper most tip region. Turning in the tip region produces a stratified effect in heat transfer, with one very high stream coming off the center divider, and one very low stream above this. The separation zone immediately downstream of the center divider tip (seen as a low no-data spot) is quite large. The secondary "impingement" of the turning flow against the far wall of Passage 2 produces an enhanced heat transfer region that washes up near the tip corner. The path of the turned flow in Passage 2 is evident from the interaction with the turbulators. Figure 8 shows a close-up of the tip region with a modified color scale to accentuate the turning flow and vane effects on local heat transfer coefficients.

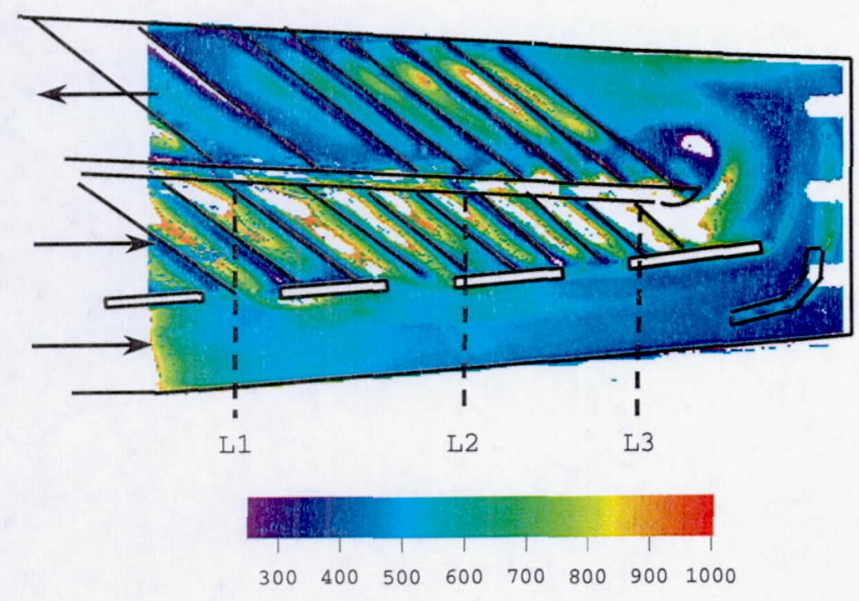

Figure 7. Heat Transfer Coefficient Distribution for Channel Inlet $\mathrm{Re}=83,500(\mathrm{~W} / \mathrm{m} 2 / \mathrm{K})$
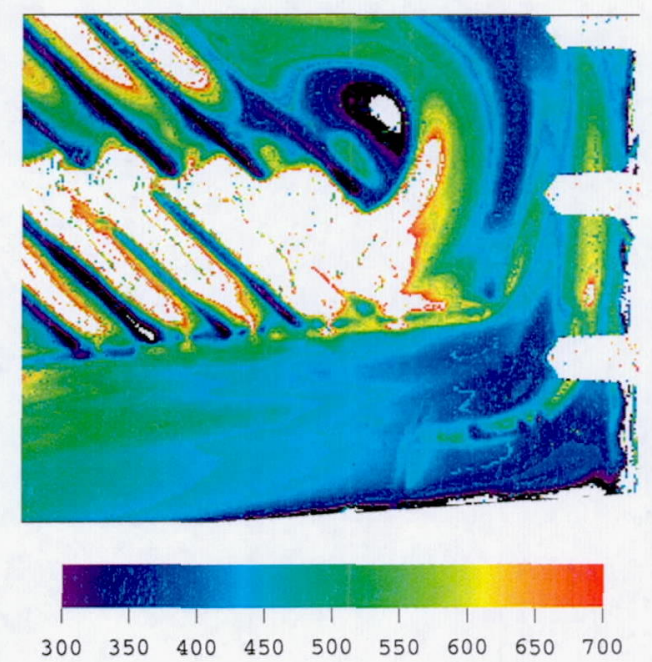

Figure 8. Heat Transfer Coefficient Distribution for Channel Inlet $\mathrm{Re}=\mathbf{8 3 , 5 0 0}$ Scaled to Show Turn (W/m2/K)

To compare the heat transfer coefficients of Figure 7 with expectations based on smooth or turbulated channel flow, a few regions may be examined which appear to have developed flow conditions, though in reality the channel geometry is continuously changing. For the purposes of comparison, the simple fully developed, smooth channel heat transfer coefficient of Dittus-Boelter [19] is used as noted in Holman [20],

$$
h=(k / D) * .023 \operatorname{Re}^{0.8} \operatorname{Pr}^{0.4} \text {. }
$$

In Figure 7, three locations in Passage 1 are denoted by labels L1, L2, and L3. Table 2 presents the Passage 1A and 1B Reynolds numbers at these locations based on the flow split of Figure 6. Also presented are the smooth duct and measured heat transfer coefficients at these locations. Near the thermal entry region of Passage $1 \mathrm{~A}$ (location L1), heat transfer is slightly above the expected value, most likely due to the thermal entry effect from the start of the heater. Upstream of the heater, the passages are of constant cross-section to develop the flow. In Passage 1B, the enhancement level is about 2.8, which is consistent with a well turbulated channel flow. Further up the channel at location L2, heat transfer in Passage 1A is decreased well below the smooth channel expected value. While this is somewhat surprising given the diversion of flow from $1 \mathrm{~B}$ into $1 \mathrm{~A}$ in this region, this added flow is not aiding heat transfer in the apex region of $1 \mathrm{~A}$. Only those areas of $1 \mathrm{~A}$ closest to the segmented rib dividers appear to have heat transfer levels near the expected values. Remember too that this is an accelerating channel flow. Passage 1B enhancement at location $\mathrm{L} 2$ remains very high. At the location L3 just prior to the tip, Passage 1A heat transfer has declined even further, which is an extension of the effect seen at L2, but also a consequence of the influence of the tip region. Here, Passage 1B enhancement is still at least 1.6, though the actual value is undetermined due to lack of data. 


\begin{tabular}{|c|c|c|c|c|}
\hline Location & Re Passage 1A & h sm ooth & h m easured & h m eas $/ \mathrm{h}$ sm ooth \\
\hline L1 & 63100 & 440 & 510 & 1.159 \\
\hline L2 & 115100 & 785 & 490 & 0.624 \\
\hline L3 & 104800 & 782 & 440 & 0.563 \\
\hline Location & Re Passage 1B & h sm ooth & h m easured & h m eas $/ \mathrm{h}$ sm ooth \\
\hline L1 & 91250 & 284 & 800 & 2.817 \\
\hline L2 & 62700 & 245 & 810 & 3.306 \\
\hline L3 & 134250 & 631 & $>1000$ & $>1.585$ \\
\hline
\end{tabular}

Table 2. Comparison of Passage 1 Heat Transfer Coefficients with Smooth Channel Expectations (W/m2/K)

Passage 2 contains the total flow rate, and so an estimate of the expected heat transfer coefficient can be made clearly here. Just after the separation from the center divider, $\mathrm{Re}$ is about 131,000 and the expected smooth heat transfer coefficient is $410 \mathrm{~W} / \mathrm{m} 2 / \mathrm{K}$. Here, the enhancement level is seen to be about 1.5 just prior to the first turbulator. Midway down the passage, the enhancement is about 2.2 as the turbulation is involved once again. Near the exit of the passage, the expected smooth wall heat transfer is down to 230 $\mathrm{W} / \mathrm{m} 2 / \mathrm{K}$ as the area opens up. Enhancement here is about 2 .

Figures 9 shows the tip region heat transfer coefficient distributions for a lower Passage 1 inlet $\operatorname{Re}$ of 46,500. All of the previously noted features of the flow and heat transfer are the same at this lower Re condition. A direct comparison of the heat transfer coefficients is made by dividing the results at $\operatorname{Re}=83,500$ by those at $\mathrm{Re}=46,500$, as shown in Figure 10. The overall ratio of these results is 1.6 , which confirms a heat transfer dependence of $\mathrm{Re}^{0.8}$. Small spots or strips of lesser of greater ratio are due to the slightly altered size of separation and turning zones for the two Re conditions.
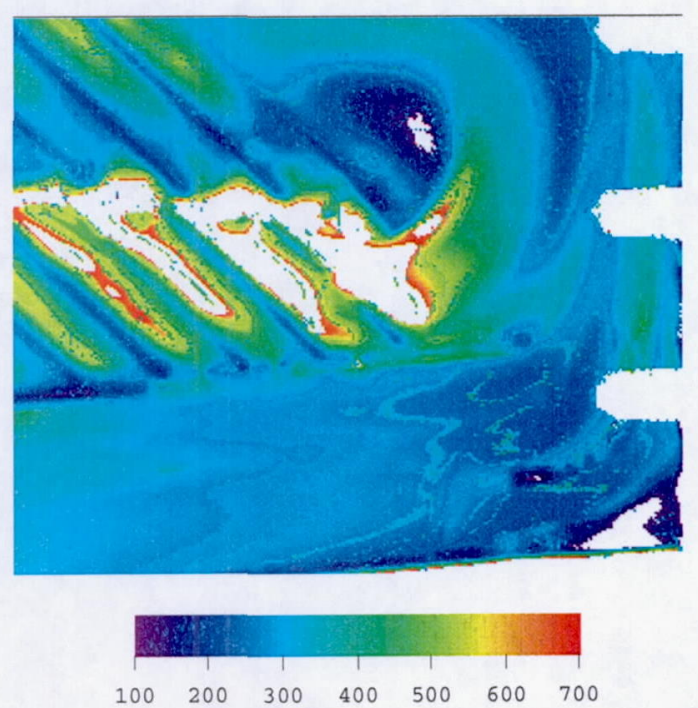

Figure 9. Heat Transfer Coefficient Distribution for Channel Inlet $R e=46,500(\mathrm{~W} / \mathrm{m} 2 / \mathrm{K})$
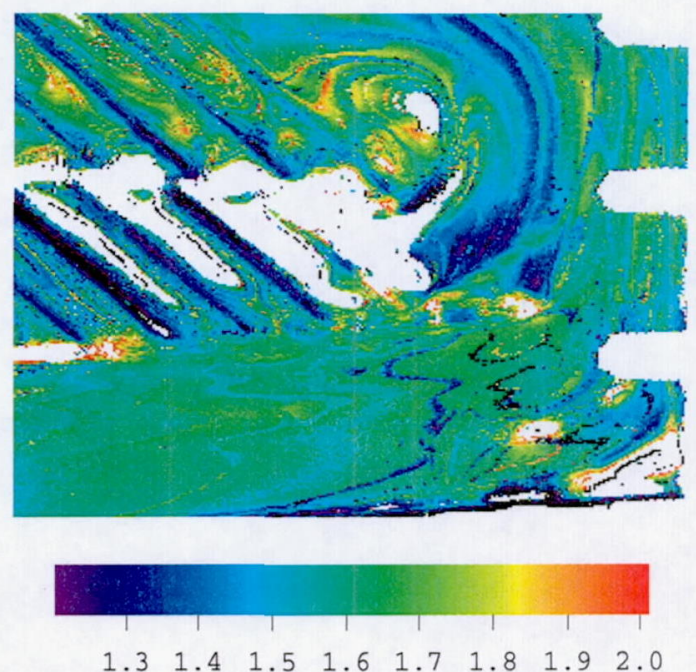

Figure 10. Normalized Heat Transfer Coefficient
Distribution $h(\operatorname{Re}=83,500) / h(\operatorname{Re}=46,500)$

\section{CONCLUSIONS}

Full-surface internal heat transfer coefficient distributions have been obtained for a complex two-pass serpentine model of a realistic blade trailing edge region. The model involves a trailing edge split passage with aspect ratio of $14: 1$, turbulated passages, and a tip turning vane, all with the inclusion of channel convergence from root-to-tip, as well as channel taper towards the trailing edge. Examination of the heat transfer and pressure distribution data clearly show the salient characteristics of the geometry and resulting thermal response. Features of separation, turning flow, low heat transfer, and impingement are all shown. Overall heat transfer levels respond with the expected dependence of $\mathrm{Re}^{0.8}$. This detailed data is used in Part 2 of the present study as validation for CFD prediction.

\section{ACKNOWLEDGMENT}

This study was prepared with the support of the U.S. Department of Energy, under Cooperative Agreement No. DE-FC21$95 \mathrm{MC} 31176$. However, any opinions, findings, conclusions, or recommendations expressed herein are those of the author and do not necessarily reflect the views of the DOE.

\section{NOMENCLATURE}

A passage cross section flow area $(\mathrm{cm} 2)$

$\mathrm{A}_{\mathrm{h}} \quad$ heater area $(\mathrm{cm} 2)$

D local passage hydraulic diameter $(\mathrm{cm})$

e turbulator height $(\mathrm{mm})$

h local heat transfer coefficient $(\mathrm{W} / \mathrm{m} 2 / \mathrm{K})$

$\mathrm{k}$ thermal conductivity of air (W/mK)

m passage flow rate $(\mathrm{kg} / \mathrm{s})$

$\mathrm{Q}_{\text {wall }} \quad$ total heater power (W)

$\mathrm{P} \quad$ turbulator pitch spacing $(\mathrm{mm})$

Pr Prandtl number

Re channel local Reynolds number $=\rho \mathrm{VD} / \mu$

$\mathrm{T}_{\text {air }} \quad$ channel bulk mean fluid temperature $\left({ }^{\circ} \mathrm{C}\right)$; average of inlet, tip turn, and exit measurements 
$\mathrm{T}_{\text {surface }} \quad$ wall temperature from the liquid crystal $\left({ }^{\circ} \mathrm{C}\right)$

$\mathrm{V}$ local channel average fluid velocity

$\mu \quad$ viscosity

$\rho \quad$ air density

\section{REFERENCES}

[1] Han, J.C. and Dutta, S., 2001, "Recent Developments in Turbine Blade Internal Cooling", in Heat Transfer in Gas Turbine Systems, Annals of the New York Academy of Sciences, Vol. 934, pp. 162-178.

[2] Weigand, B., Semmler, K., and von Wolfersdorf, J., 2001, "Heat Transfer Technology for Internal Passages of Air-Cooled Blades for Heavy-Duty Gas Turbines", in Heat Transfer in Gas Turbine Systems, Annals of the New York Academy of Sciences, Vol. 934, pp. 179-193.

[3] Webb, R.L, Eckert, E.R.G., and Goldstein, R.J., 1971, "Heat Transfer and Friction in Tubes with Repeated-Rib Roughness", Int. Journal of Heat and Mass Transfer, Vol. 14, pp. 601-617.

[4] Burggraf, F., 1970, "Experimental Heat Transfer and Pressure Drop with Two-Dimensional Turbulence Promoter Applied to Two opposite Walls of a Square Tube", in Augmentation of Convective Heat and Mass Transfer, Eds. Bergles and Webb, ASME, pp. $70-79$.

[5] Han, J.C., Glicksman, L.R., and Rohsenow, W.M., 1978, "An Investigation of Heat Transfer and Friction for Rib-Roughened Surfaces", Int. Journal of Heat and Mass Transfer, Vol. 21, pp. 1143-1156.

[6] Han, J.C., Park, J.S., and Lei, C.K., 1984, "Heat Transfer Enhancement in Channels with Turbulence Promoters", Paper No. 84-WA/HT-72, ASME.

[7] Rau, G., Cakan, M., Moeller, D., and Arts, T., 1998, "The Effect of Periodic Ribs on the Local Aerodynamic and Heat Transfer Performance of a Straight Cooling Channel", Journal of Turbomachinery, Vol. 120, pp. 368-375.

[8] Schabacker, J., Boelcs, A., and Johnson, B.V., 1998, "PIV Investigation of the Flow Characteristics in an Internal Coolant Passage with Two Ducts Connected by a Sharp 180-deg Bend", Paper No. 98-GT-544, IGTI Turbo Expo, Stockholm.

[9] Shih, T.I-P., Lin. Y.-L., Stephens, M.A., Chyu, M.K., and Civinskas, K.C., 1998, "Flow and Heat Transfer in a Ribbed U-Duct under Typical Engine Conditions", Paper No. 98-GT-213, IGTI Turbo Expo, Stockholm.

[10] Chen, Y., Nikitopoulos, D.E., Hibbs, R., Acharya, S., and Myrum, T.A., "1996, "Detailed Mass Transfer Distribution in a Ribbed Coolant Passage", Paper No. 96-WA/HT-11, ASME Int. Mech. Engr. Congress, Atlanta.

[11] Chyu, M.K. and Natarajan, V., 1995, "Surface Heat Transfer from a Three-Pass Blade Cooling Passage Simulator", Journal of Turbomachinery, Vol. 117, pp. 650-656.

[12] Funazaki, K., Ishizawa, K., and Yamawaki, S., 1998, "Surface Heat Transfer Measurements of a Scaled Rib-Roughened Serpentine Cooling Passage by Use of a Transient Liquid Crystal Technique", Paper No. 98-GT-515, IGTI Turbo Expo, Stockholm.

[13] Taslim, M.E., Li, T., and Spring, S.D., 1998, "Measurements of Heat Transfer Coefficients in Rib-Roughened Trailing-Edge Cavities with Crossover Jets", Paper No. 98-GT-435, IGTI Turbo Expo, Stockholm.

[14] Abuaf, N. and Kercher, D.M., 1993, "Heat Transfer and Turbulence in a Turbulated Blade Cooling Circuit", Journal of Turbomachinery, Vol. 116, pp. 169-177.
[15] Hollingsworth, D.K., Boehman, A.L., Smith, E.G., and Moffat, R.J., 1989, "Measurement of Temperature and Heat Transfer Coefficient Distributions in a Complex Flow Using Liquid Crystal Thermography and True-Color Image Processing", ASME Collected Papers in Heat Transfer, pp. 35-42.

[16] Farina, D.J. and Moffat, R.J., 1994, "A System for Making Temperature Measurements Using Thermochromic Liquid Crystals", Report No. HMT-48, Thermosciences Division, Stanford University.

[17] Farina, D.J., Hacker, J.M., Moffat, R.J., and Eaton, J.K., 1994, "Illuminant Invariant Calibration of Thermochromic Liquid Crystals", Experimental Thermal and Fluid Science, Vol. 9, pp. 1-9.

[18] Kline and McClintock, 1953, "Describing Uncertainties in Single-Sample Experiments", Mechanical Engineering, January 1953.

[19] Dittus, F.W. and Boelter, L.M.K., 1930, University of California at Berkeley Publications in Engineering, Vol. 2, p. 443.

[20] Holman, J.P., 1976, Heat Transfer, McGraw-Hill Book Co., $4^{\text {th }}$ edition, p. 204. 